\title{
Dialectics of Mental Entities: Notion vs Term
}

\author{
Tatiana Tyurneva ${ }^{1}$, Natalia Shchurik $^{1}$,Galina Evseeva $^{1 *}$, and Olga Krapivkina $^{2}$ \\ ${ }^{1}$ Irkutsk State University, 664025 Irkutsk, Russia \\ ${ }^{2}$ Irkutsk National Research Technical University, 664074 Irkutsk, Russia
}

\begin{abstract}
Modern linguistics equally uses notion and term definitions. Very often even scientists do not differentiate these phenomena using them as synonyms. Moreover, even dictionaries treat them as synonyms. The authors of the article try to distinguish these entities. According to the pioneer paper of A.M. Kaplunenko "Concept - Notion - Term: evolution of semiotic entities in the context of discursive practices" it is possible to make an attempt to prove their difference. Within Discourse of Consensus, participants use notions with limited scope and content constructing the interpretation vector on the basis of key characteristic features of the notion. Under umbrella of Discourse of Expert Community terms system is formed. The duality of these entities brings them into constant dynamics where knowledge may develop from the notion to the term as well as from the term to the notion.
\end{abstract}

\section{Introduction}

Nowadays scientific community is disputing mental entities differentiation and their possible correlation with a certain discourse type [1-4]. We would focus on the notion and term, which have long been considered mainly in the frame of logic and philosophy.

The purposes of this paper are twofold. The first is to consider the notion and term on the basis of belonging to a certain type of discursive community. The second is to illustrate the vector of mental entities interpretation.

Notions are often defined as one of the main forms of thinking that is why its important role in cognition is emphasized. Transition from a sensual step of cognition to abstract thinking is characterized by moving from perceptions and representations to the reflection of the world in forms of notions, judgments and theories as it is through the notions that thinking acquires the character of the generalized reflection of reality.

\section{Methods and material}

For the purpose of the present research, an analytical method is used. The analysis was carried out using 36 technical and legal texts available on the Internet. Discourse analysis aims to research different types of discursive practices and types of discourse. Interpretative approach helps to make a border between notion and term.

\section{Notion within Discourse of Consensus}

Establishment of rationalism principle as a manifestation of knowledge, science and technology progress gave rise to Discourse of Consensus. European rationalism giving up on scholastic speculation methods addressed the issue of scientific knowledge basis attempting to prove that reason is the only reliable source. The idea was declared by Bacon in his statement Knowledge itself is power. Rationalist thinking is referred to as a notional activity because operating with notions enables science to perform its main cognitive functions: description, explanation and prediction of phenomena. For this very reason, each science has its own language. Fundamental requirement of classical rationalism is to find absolute truth having general meaning for any human mind.

When consensus building, scientists develop a notion of the object under study, choose a language sign which would nominate it. "Notions are entities which people agree upon, construct in order to have common language when debating" [5, p. 5].

Arguing about notion and its content, it is necessary to emphasize that the mental entity possesses certain characteristic features that help to distinguish notions from concepts or terms. Since the notion is a general understanding of something, its characteristics contribute to the delineation of any phenomena, providing an opportunity to define the object of the study and distinguish it from a number of similar ones. Let us say that "snow" or "blood" are natural-scientific notions, the distinctive features of which are evident to any society member. People should not judge at first sight whether all characteristics of the notion correspond to the notion object. Moreover the object is researched on the part of its various properties. Once this is done "the object 1 is finally coming under the notion 1 , which means it is attributed to the whole number of characteristic features" [6, p. 50]. 
Notions have a limited number of characteristics selected from concepts and negotiated by communicants. Limited number of characteristics encourages consensus of different views. By limiting individual characteristics, individual interpretants give way to a single interpretant. Limitation of characteristics encourages cooperation in perceiving deeper, implicit characteristics of the object.

A notion as a basis for Discourse of Consensus can be presented in a Venn diagram:

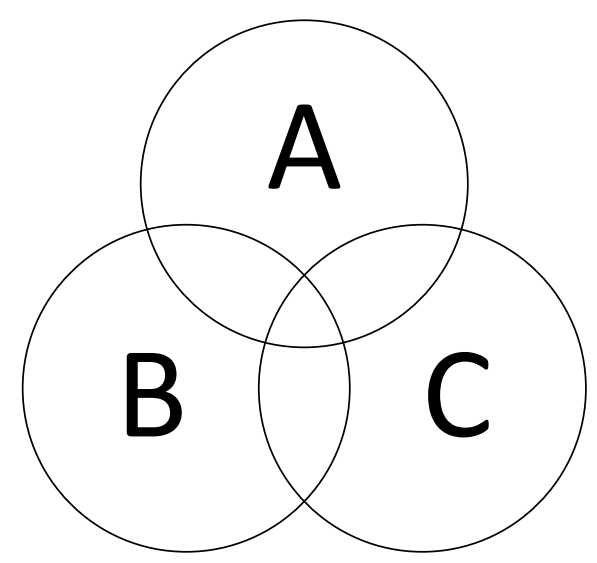

Fig. 1. Notion formation.

A is characteristics which the first communicant attributes to the object; $\mathrm{B}$ is characteristics which the second communicant attributes to the object; $\mathrm{C}$ is characteristics which the third communicant attributes to the object; intersection area is a limited number of characteristics which were selected from concepts as a result of negotiations.

Let us take a closer look at a number of examples.

The freedom of belief and conscience and the freedom to profess religious and philosophical beliefs are inviolable.

Democracy and freedom of thought and expression should therefore be recognized as inalienable rights about which there should be no discrimination.

The Principles guarantee freedom of creation and unimpeded development of cultural and artistic processes.

Here are the definitions of a lexical unit "freedom": the power or right to act, speak, or think as one wants [7]; the condition or right of being able or allowed to do, say, think, etc. whatever you want to, without being controlled or limited [8]; the state of being free, independent, without restrictions [9]. Based on the definitions, the key features of the "freedom" are highlighted: being free, have a right. Common for a wide range of interpreters, characteristics represent the main feature of the language sign: "commonality" (Fig.2).

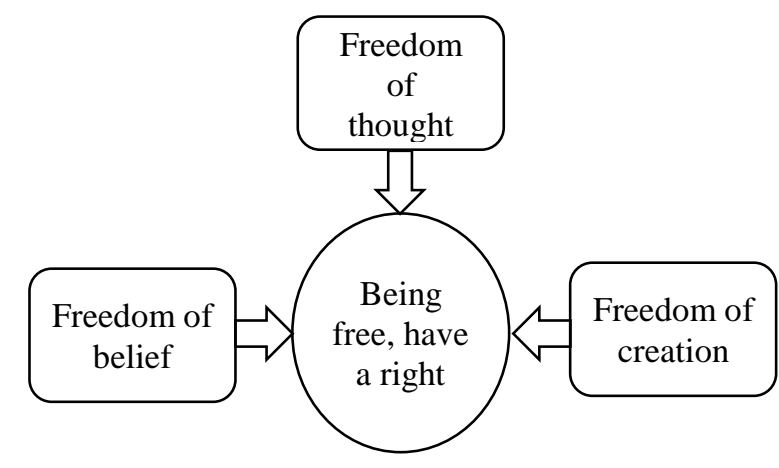

Fig. 2. Vectors of sign interpretation.

Freedom is understood as independence, lack of restrictions and restraints and human rights. The key semantic signs allow coming to a common denominator and constructing a common vector of interpretation for all participants of the discursive practice which we will define as Discourse of Consensus after prof. A. Kaplunenko [1].

\section{Term within Discourse of Expert Community}

Analyzing notion and its content, it is necessary to emphasize that the mental entity possesses certain characteristic features that help to distinguish it from the concept or term. The notion can be defined as a thought, which summarizes objects by the system of characteristic features common only for these selected objects. The objects are united into a category and separated from others. Developing the theory of notion, it is supposed that the notion is universal and unites native speakers who are participants of discourse. "Dialectical thinking depends on consciousness ability to overcome differences within Discourse of Consensus"[2].

In the process of communication, and therefore, interaction, the participants of the discourse may take part in a specific conversation with expert commentary. A characteristic feature of Discourse of Expert Community is the use of terms familiar only to a certain range of specialists. The semiotic entities will be interpreted by a layman completely different because of the lack of special knowledge about the object.

Special knowledge is used for handling professional issues, generating expert opinions and ideas. The term serves as a specialized limiting nomination of objects, phenomena, their properties and relations in certain professional settings [10].

"Terminus" is the boundary that originally was a materially planned and therefore meant frontier pillar, border stone, border sign in general. It is a limit of the area of culture [11]. Within the expert community, terms are tools of professional thinking; therefore, representatives of expert communities demand the term meaning to be clear and unique. If the phenomenological nature of the concept results in communication failure, multiple interpretants of the sign, the term has a limited number of 
characteristics, reducing the likelihood of different interpretations.

In this connection it will be appropriate to assume that terms should be unambiguous, i.e. they should not have a large number of synonyms within a certain expert community. Terms should be accurate, concise and stylistically neutral. The term content and scope are strictly limited - one sign corresponds to one meaning within a certain term system. Language signs with a dense content and limited scope that are functioning in Discourse of Expert Community as a result become the language of a special field of scientific knowledge.

Terms should avoid both polysemy and interpretation based on intentional experience or pure feelings. According to Husserl, consciousness as experienced from the first-person point of view is based on sensory perception. As a result, experience is becoming a source of idea creation, which means a person gains knowledge through experience that can be characterized as an individual's cognitive context of interpreting that is unlikely to be appropriate when dealing with the language of experts.

Joining the discourse community, the subject adopts professional language, demonstrates his/her expertise, shows that knowledge is not available for laypersons. Interpretation of professional phenomena is expert conceptualization based on expertise and terminology rather than on phenomenological experience. Communication failure is not typical for expert communities as the term is defined with a set of characteristics which is common for each communicant.

The expert communicants do not need to describe terms employed in their discourse practices and create semantic redundancy. Their discourse interaction can be presented in the Venn diagram as follows:

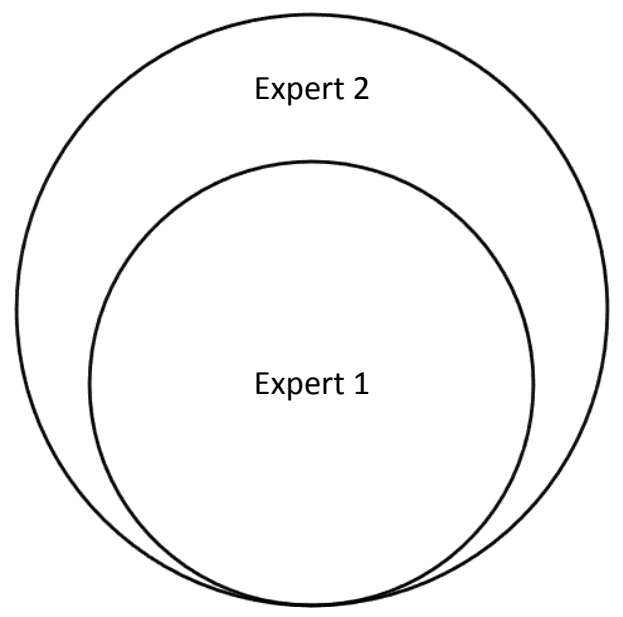

Fig. 3. Expert-expert interaction.

Figure 3 shows that experts have common legal expertise which allows them to interact using terms of the legal discourse community.

Thus, the evolution of mental entities can be described as follows: at the first stage, the mental entity has multiple phenomenological characteristics and lacks a united nomination (concept); at the second stage, overcoming differences in knowledge encourage formation of a united nomination (notion); at the final stage, the mental entity acquires characteristics which are relevant for a specific expert community (term) (see Figure 3 ).

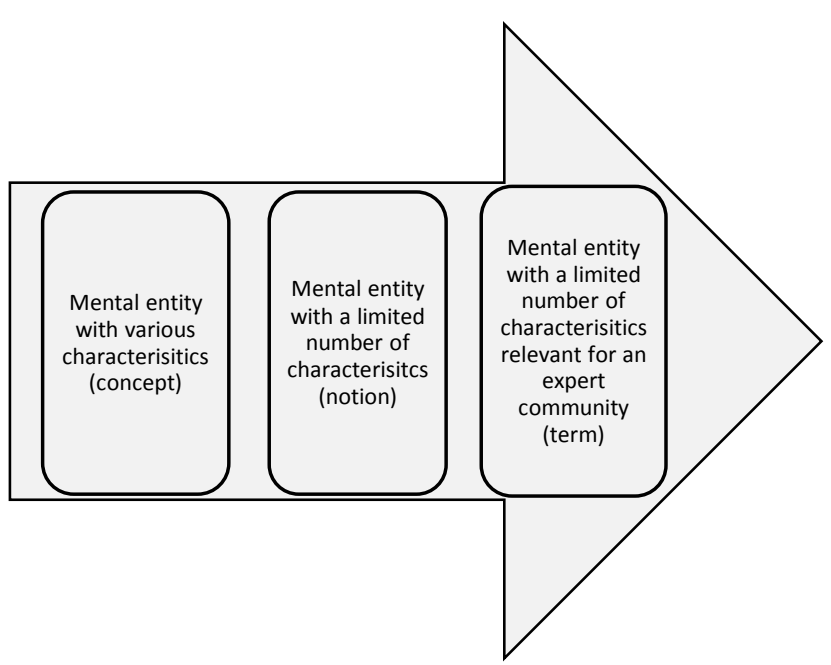

Fig. 4. Evolution of mental entities.

Let us consider a number of examples containing the language sign "freedom".

Factors like foreign airlines utilizing the sixth freedom of air, expansion of capacity entitlements under bilateral air service agreements with foreign countries and lower utilization of India's own capacity entitlements are responsible for the same.

Almost all countries are partners to the Convention but some have observed this freedom better than others. When the Korean airliner lost its way over Soviet air space a few years ago and was shot down, the Soviet Union (among other offenses!) violated this First Freedom.

These fragments of expert discourse contain such terms as "first freedom" and "fifth freedom". When translated into Russian loan translation is applied. However, without additional background knowledge correct interpretation of these terms is not possible, since the numerals (first, fifth) do not bind to "freedom" in aviation context.

Associatively an interpreter can correlate the term "first/fifth freedom" with the freedoms of the person enshrined in the Constitution, but this characteristic feature will not lead to the correct vector of interpretation. In discourse of experts these terms should be understood as "freedom of airspace". They constitute nine sets of civil aviation rules that entitle airlines to enter the airspace of another country and land there. Thus, the term "third freedom" refers to the right to fly over a foreign country without landing and "sixth freedom" allows flying from a foreign country to another while stopping in one's own country for non-technical reasons (Fig. 5). 


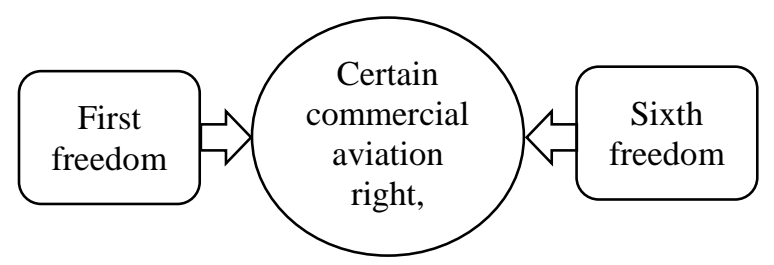

Fig. 5. Term interpretation.

Let us analyze the same language sign but in another expert community.

Fully functional androids and multi-legged mobile robots can have more than 20 degrees of freedom. An example is Project Nao, an intelligent android designed for the consumer market. Nao, which looks superficially like a large space-age doll, has 25 degrees of freedom. (6)

In this example we observe the use of the term, the content of which is known to the participants of expert community discourse, therefore experts' interpretants ${ }^{\mathrm{a}}$ aspire to the common object of true reality and are not directional. Degrees of freedom, in a mechanics context, are specific, defined modes in which a mechanical device or system can move. The term "degree of freedom "is widely used to define the motion capabilities of robots.

In the scientific literature it is generally recognized that terms are words or phrases of a special use that differ from the units of the vernacular language. O. Zjablova in her study of economic texts suggests that terms may go beyond their natural habitat, which is commonly referred to as "languages for special purposes" [12]. Terminological units often lose their specific features becoming a unit of the vernacular language or converging with everyday vocabulary. However, there is a possibility of a reverse transformation when a unit of vernacular character acquires new characteristics and further becomes a term. The quantity of specific features distinguishing term from everyday lexis depends on knowledgebranch, type of text, communicative situation, participants of conversation, etc.

It is interesting to note that in modern semiosis, knowledge may develop not only from the notion to the term, but from the term to the notion as well. This is occurring, for example, to the term race which is often involved into Discourse of Differences by replacing the name race with descriptions and names allegedly lacking negative connotations: groups which have been historically discriminated against, underrepresented minorities, African-Americans, Hispanics, and Native Americans.

Let us provide some examples.

During all relevant periods, the University has considered African-Americans, Hispanics, and Native Americans to be "underrepresented minorities $<\ldots>$.
$<. .>$ racial and ethnic diversity with special reference to the inclusion of students from groups which have been historically discriminated against, like AfricanAmericans, Hispanics and Native Americans.

For decades, $\$ 5$ of the Voting Rights Act of 1965, through its preclearance requirement, worked to safeguard long obstructed access to the ballot by AfricanAmerican citizens.

The principles of equality and non-discrimination should ensure that no group is left behind and that groups that have historically been discriminated against receive special protection.

These data tend to underscore the importance of programs targeting women and underrepresented minorities in maintaining a diverse student and faculty population.

Race is considered as not only one of the most frequently misunderstood names in the legal discourse, it is also a dangerous sign that can reinforce prejudice and discrimination [13].The analysis revealed that race is elusive and has no reliable definition. It is not merely vague or incoherent, but worse, is a pernicious concept. Negative connotations of race encourage the argument that law should discontinue use of the term and replace it by more precise terms, including ethnicity, continent of origin, ancestry, descent. Thus, in modern semiosis we can observe devolution of the mental entity. The challenge is to find a name that captures all relevant connotations of the name race, a task that is most probably impossible. For example, the term ethnicity as a substituting term refers to the fact or state of belonging to a social group that has a common national or cultural tradition [14], while race suggests classification of people by their physical characteristics. Origin is also not appropriate as it is problematic in terms of ancient human history. Many researchers argue that human beings originated in Africa are a subset of the population that walked north, losing their skin pigmentation in order to adjust to colder, less sunny climates.

\section{Conclusion}

Having examined the semiotic essence within the classification of discursive practices, which is mainly based on socialization of viewpoints of discourse participants, it can be concluded that:

1) within Discourse of Consensus participants use notions with limited scope and content constructing the interpretation vector on the basis of key characteristic features of the notion;

2) Discourse of Expert Community forms the basic nomenclature, a system of names used in a particular specialist field. The system of naming things within Discourse of Expert Community helps to differentiate

\footnotetext{
a'The term interpretant is used after Charles Sanders Peirce's triadic theory of the sign.
} 
terms from notions. Terms have the narrowest scope and specific content which causes ambiguity of the term and manifests final interpretation of a language sign.

In modern semiosis, knowledge may develop from the notion to the term, as well as from the term to the notion.

Semiotic analysis emphasizes one promising research venue - dialectical transition from one discourse practice to another one in violation of the described traditional evolutionary scheme Discourse of Consensus - Discourse of Expert Community.

\section{References}

1. A.M. Kaplunenko, Concept - Notion - Term: evolution of semiotic entities in the context of discursive practices (ISLU, Irkutsk, 2007)

2. T.V. Tyurneva, Analysis of linguistic and semiotic context of EDUCATION: concept, notion, term: on the material of the English language (Philology Cand. Diss., ISLU, Irkutsk, 2012).

3. T.V. Tyurneva, N.V. Schurik, Modern research of Social Problems 9 (1), 115-125 (2017).

4. O. Krapivkina, Journal of language and cultural education 3, 77-92 (2017).

5. V.Z. Demyankov, Issues of Cognitive Linguistics $\mathbf{3}$, 5-10 (2005)

6. H. Sigwart, Logic Vol. 1. The Judgment, Concept, and Inference (Territory of Future, Moscow, 2005).

7. OWD Oxford Wordpower Dictionary (Oxford : Oxford University Press, 2003)

8. CED Collins English Dictionary. URL: https://www.collinsdictionary.com/dictionary/englis $\mathrm{h}$

9. MLWD Merriam-Webster's Learning Dictionary. American English Dictionary for Students of ESL, EFL, and the TOEFL. URL: https://www.merriamwebster.com/dictionary/American\%20English

10. O.A. Krapivkina, Advances in Social Science, Education and Humanities Research, Proceedings of the 7th International Scientific and Practical Conference "Current issues of linguistics and didactics: The interdisciplinary approach in humanities", 146-151 (2017)

11. P.A. Florensky, At the rig of thought (Akademicheskij proekt, Moscow, 2012)

12. O.A. Zjablova, Questions of philology (Severnyj Gorod, Moscow, 2005).

13. P.I. Rose, They and we: racial and ethnic relations in the United States (New York, 1968).

14. Oxford Dictionaries (Oxford University Press, 2017) 